\title{
The Effects of Income Fluctuations on Rural Health and Nutrition
}

\author{
Katrina Kosec and Jie Song
}

\section{RESEARCH OVERVIEW}

How do income fluctuations affect health and nutrition outcomes, and how do these effects vary across the life cycle? Studies looking both across and within countries reveal strong correlations between income and health (Cutler et al., 2006; Adda et al., 2009; Currie, 2009; Banerjee et al., 2010; Bengtsson, 2010; Baird et al., 2011; Ebenstein et al., 2015). In terms of a causal link, some of the best identified studies of the impacts of income on health consider either extreme events that provide natural experiments-like droughts (Lohmann and Lechtenfeld, 2015; Hyland and Russ, 2019), blights (Banerjee et al., 2010), prolonged blackouts (Burlando, 2014), war and armed conflict (Akresh et al., 2012; Minoiu and Shemyakina, 2014), recessions (Bhalotra, 2010), or financial crises (Cutler et al., 2002; Van den Berg et al., 2006; Bozzoli and Quintana-Domeque, 2014; Hidrobo, 2014)—or randomized controlled trials of cash transfer programs. However, extreme events can have unique behavioral impacts, such as reduced life satisfaction (Luechinger and Raschky, 2009), increased risk aversion (Cameron and Shah, 2015), and reduced aspirations for the future (Kosec and Mo, 2017), which smaller fluctuations in income do not bring about. And findings from cash transfer programs may not generalize to populations not targeted by such programs. Further, evidence on the health impacts of transfers is mixed (Evans et al., 2019).

Our working paper, "The Effects of Income Fluctuations on Rural Health and Nutrition," provides causal evidence on how the income fluctuations poor households confront across the globe influence health and nutrition outcomes across the life cycle. We use individual-level data from a 13-year, nationally-representative rotating panel survey of Kyrgyzstan to estimate the effects of fluctuations in the incomes of agriculture-dependent households on the heights and weights of young children (age 0-5) and on the incidence of overweight and obesity among children and adults. Our focus on departures of income from trend is distinct from analysis of the effects of long-term changes in income. It offers insight into how health responds to income fluctuations that are ubiquitous in developing countries rather than the impacts of global shifts in a country's prosperity. We address the endogeneity of income to health and consumption using an instrumental variables approach; we instrument for income with predicted income, obtained using the household's initial period share of income from six different revenue sources, agricultural production costs from two different sources (crop and livestock), and aggregate growth rates of each of these eight revenues and costs over time. We find that young children (age 0-5) exposed to reductions in income experienced reductions in height. At the same time, older children and adults saw decreases in $\mathrm{BMI}$ and-for adults-decreases in the incidence of overweight. 


\section{DATA AND METHODS}

Our data source is the Kyrgyzstan Integrated Household Survey (KIHS), a nationally representative, rotating panel household survey carried out quarterly starting in 2003. For consistency in income codes, we use data for the 13 years spanning 2004-2016. We include in our sample for analysis households earning at least some income from agriculture during their first year in the sample, which constitute 61.8 percent of household-year observations from the KIHS sample. In total, we have 35,961 unique individuals from 8,845 households in our main sample for analysis.

We follow a large literature based on Bartik (1991) to identify the causal effects of fluctuations in income. Specifically, we predict logged total household income in year $t=n$ by taking the baseline (year $t=0$ ) values of six sources of household revenue (income from the non-agricultural sector, crop production, livestock sales, meat production, hunting/ gathering, and production of processed food) and two costs (crop production costs and livestock production costs) that jointly sum to total income, and multiplying each by the oblast (i.e. region; there are eight in our sample) $\times$ area type (rural or urban) aggregate growth rate in this revenue (or cost) source between $t=0$ and $t=n$. Formally:

$$
A_{i, j, k, t}=\sum_{r=1}^{6}\left(\text { revenue }_{j, r, t=0} \times\left(1+g_{j, k, r, t}\right)\right)-\sum_{c=1}^{2}\left(\operatorname{cost}_{j, c, t=0} \times\left(1+g_{j, k, c, t}\right)\right)
$$

where $j$ indexes households, $k$ indexes the oblast (i.e. region) in which the household resides, $t$ indexes years, and $g_{j, k, r, t}$ and $g_{j, k, c, t}$ are the average growth rates of revenue source $r$ and cost source $c$, respectively, between year $t=0$ and year $t$ in the oblast $\times$ area type. We then use this predicted (i.e. "projected") household income variable as an instrument for actual total household income. Using this instrumental variables strategy, our first and second stage equations are:

$$
\begin{gathered}
O_{i, j, k, t}=\pi_{0}+\pi_{1} \log \left(H_{j, k, t-s}\right)+\pi_{2} X_{j, k, t=0}+\pi_{3} Y_{i j k t}+\gamma_{k}+\eta_{t}+u_{i j k t} \\
\log \left(H_{j, k, t-s}\right)=\theta_{0}+\theta_{1} \log \left(A_{j, k, t-s}\right)+\theta_{2} X_{j, k, t=0}+\theta_{3} Y_{i j k t}+\delta_{k}+\sigma_{t}+v_{i j k t}
\end{gathered}
$$

where $i$ indexes individuals, $s$ is the chosen lag structure, in years (either 1 or 2). $O_{i, j, k, t}$ is a health or nutrition outcome in our main analysis, which is measured in the first quarter of the year (January-March). $H_{j, k, t-s}$ is total annual household income; it is the sum of the values of six sources of household revenue net of the two costs of agricultural production. $X_{j, k, t=0}$ is a vector of household-level controls, taken from the first year the household $j$ entered the sample, and $Y_{i j k t}$ is a vector of individual-level controls. $\gamma_{k}$ and $\delta_{k}\left(\eta_{t}\right.$ and $\left.\sigma_{t}\right)$ are oblast (year) fixed effects in the second and first stages, respectively. Our year fixed effects absorb the impacts of nationwide movements in revenues from different sectors over time, while our oblast fixed effects capture regional differences in the composition of income. Importantly, identification in no way comes from endogenous household decisions to change the household's relative reliance on different sectors (e.g., the non-agricultural sector vs. crop agriculture) over time. We further control for the logged value of initial (year $t=0$ ) revenue, revenue $_{j, r, t=0}$ that the household earned from each of the six revenue sources, $r,=\{1, \ldots 6\}$, and logged value of the initial year costs, $\cos _{j, c, t=0}$ that the household incurred from each of the two cost sources, $c,=\{1, \ldots 2\}$. And we also control for the interaction of each logged income or cost with a linear time trend, to allow households to be on different trends according to their initial reliance on different sources of revenue, or how affected they were initially by different costs. Finally, in case households are also on different secular trends according to their initial year total income, $H_{j, k, t=0}$, we additionally control for logged initial total income and its interaction with a time trend.

Our IV strategy exploits that part of household income that is due to exogenous changes in the profitability of different forms of earning income, and the costs of different ways of earning income. Our key identifying assumption is that predicted (i.e. projected) total income only affects health-related outcomes through its effects on household income. 


\section{Results}

Total household income is indeed strongly correlated with predicted income, revealing that our first stage regression meets the inclusion restriction; indeed, our first stage F statistic is always above 360 .

To interpret the magnitude of our second stage results, it is useful to consider what are the typical fluctuations in income that our sample households face. To do this, we computed the absolute value of the percentage change in annual household income relative to the previous year across the full sample. On average, households experienced an income fluctuation of 36 percent, year-over-year. Figures 1 and 2 thus show the predicted impacts of a 36 percent reduction in income on health and nutrition outcomes.

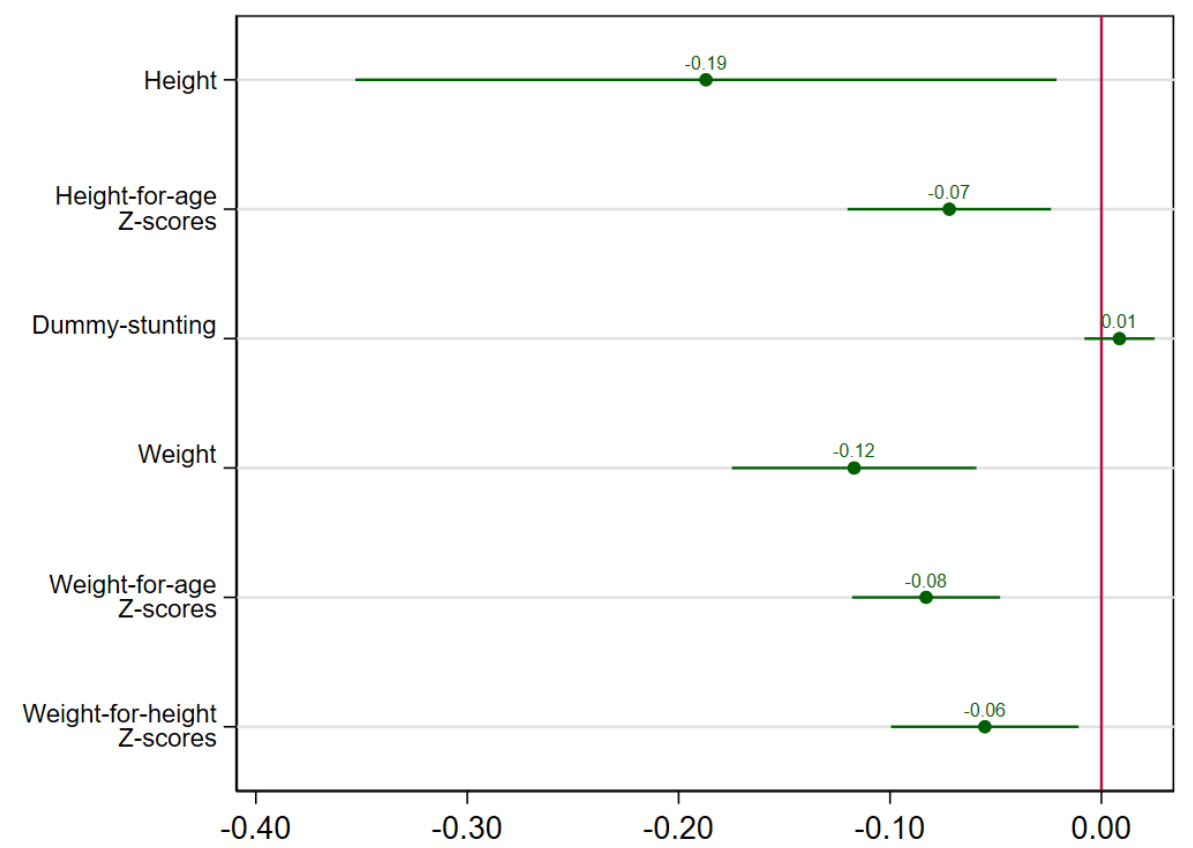

Figure 1 Effects of an average-sized negative income fluctuation on children under 5 ( $90 \%$ confidence intervals)

Reductions in household income appear to reduce height, heightfor-age Z-scores, weight, weightfor-age Z-scores, and weight-forheight Z-scores for children under five in the following yearwith all results statistical significant at the 0.1 level or higher. The probability of stunting is increased, though this effect is not significant at conventional levels. Specifically, an average-sized reduction in income of 36 percent predicts a $0.12 \mathrm{~kg}$ decline in weight, a 0.07 S.D. reduction in height-for-age Z-score, a 0.08 S.D. decrease in weight-for-age Z-score, and a 0.06 S.D. decrease in weight-for-height Z-score among children under five, compared to the international reference group (all significant at the 0.05 level or higher).

For older children (age 5-18), youth (age 18-35), and adults age over 35, we see more mixed results. Height seems to be unaffected by income fluctuations. A decrease in weight is only seen among adults over age 35. BMIs are reduced for all groups over age five, but the incidence of overweight is reduced only among adults. Specifically, among older children (age 5-18), an average-sized reduction in annual household income predicts a 0.05-point decline in BMI (significant at the 0.10 level); among youth, the same fluctuation in income predicts a larger, 0.13-point decline in BMI (significant at the 0.05 level), and a 2 percentage point decline in the probability of being overweight (significant at the 0.01 level); among adults, we see the 36 percent decrease in income predicts a $0.87 \mathrm{~kg}$ decline in weight, a 0.28 point decline in BMI, and a 4 percentage point decline in the probability of overweight (all significant at the 0.01 level).

Our discussion paper also explores the potential mechanisms through which the income fluctuations may affect health and nutrition outcomes. We find that reduced consumption of healthy foods, reduced dietary diversity, and less expenditure on healthcare may help explain the results. A channel possibly offsetting negative impacts is a decrease in fertility (Kosec and Song, 2019). 


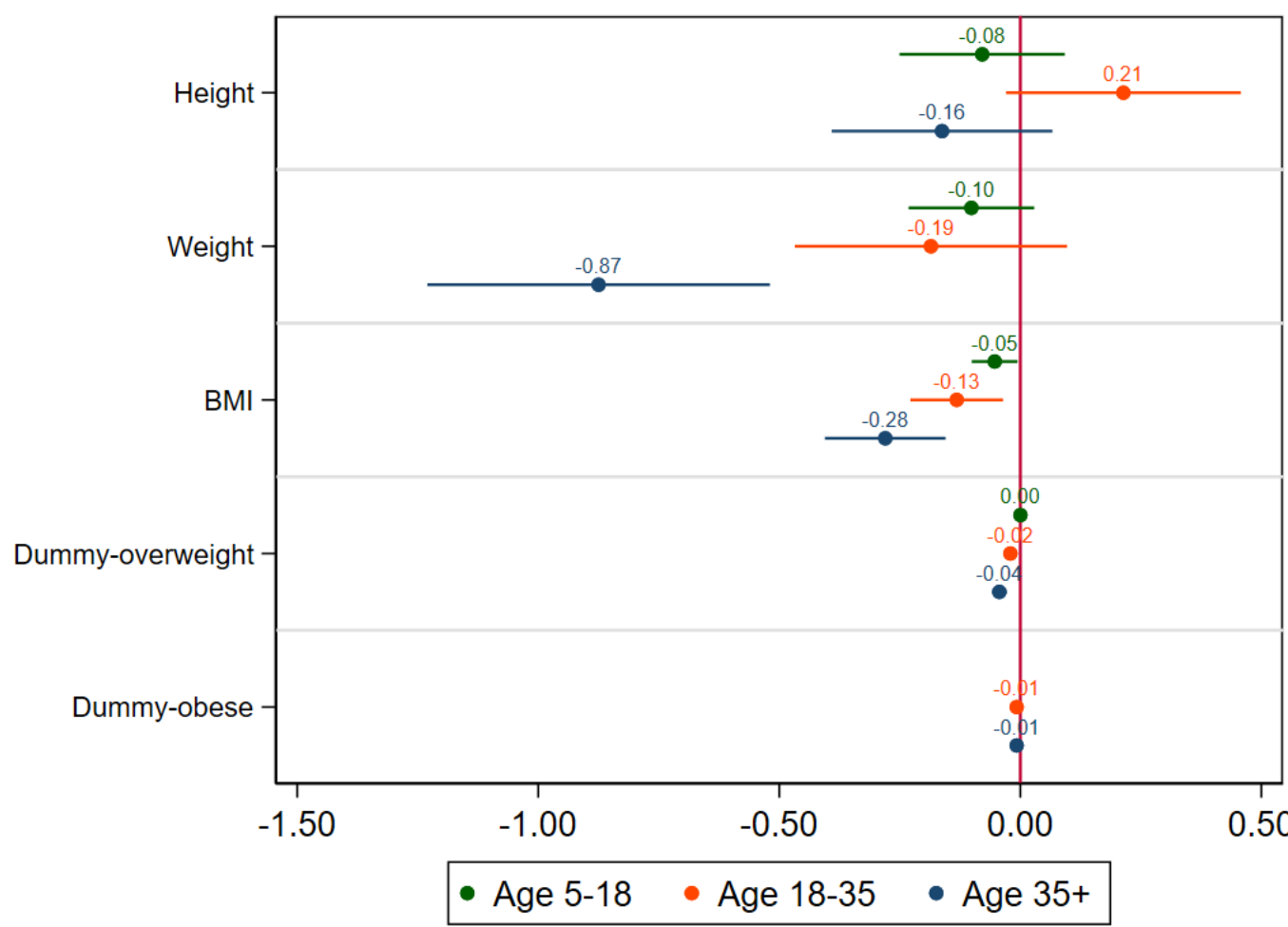

Figure 2 Effects of an average-sized negative income fluctuation on individuals over 5 $(90 \%$ confidence intervals)

\section{CONCLUSIONS AND POLICY RECOMMENDATIONS}

This study provides causal evidence from agriculture-dependent households in Kyrgyzstan that fluctuations in household income can have modest but statistically significant effects on children's long-term health and nutrition status and the BMls and incidence of overweight in adults. It also provides evidence of several channels possibly explaining these impacts.

Our findings provide both good news and bad news for the double burden of malnutrition. While reductions in income contribute to undernutrition in young children, they also reduce over-nutrition in older children and adults. They do so both by decreasing the diversity of diets, leading households to consume less of healthy foods, and reducing overall food consumption. While overall reductions in consumption may be helpful for the problem of over-nutrition in older children and adults, poorer-quality diets combined with lower consumption appear to be contributing to undernutrition in young children. This suggests the need for public health officials and practitioners in development to respond to fluctuations in household income with tailored solutions that can reduce undernutrition without also increasing over-nutrition.

\section{ABOUT THE AUTHORS}

Katrina Kosec is a Senior Research Fellow and Jie Song is a Research Analyst at the International Food Policy Research Institute (IFPRI), Washington, DC. 


\section{ACKNOWLEDGMENTS}

This research was part-funded by the CGIAR Research Program on Policies, Institutions, and Markets led by IFPRI and the Ministry of Finance of the Russian Federation under IFPRI's Collaborative Research and Capacity Strengthening Program for Enhancing Agricultural Productivity and Food and Nutritional Security in Central Asia.

\section{REFERENCES}

Adda, J., J. Banks, and H.-M. Von Gaudecker (2009). The impact of income shocks on health: evidence from cohort data. Journal of the European Economic Association 7 (6), 1361-1399.

Akresh, R., S. Bhalotra, M. Leone, and U. O. Osili (2012). War and stature: growing up during the nigerian civil war. American Economic Review 102 (3), 273-77.

Baird, S., J. Friedman, and N. Schady (2011). Aggregate income shocks and infant mortality in the developing world. Review of Economics and Statistics 93 (3), 847-856.

Bartik, T. J. (1991). Who benefits from state and local economic development policies?

Banerjee, A., E. Duflo, G. Postel-Vinay, and T. Watts (2010). Long-run health impacts of income shocks: Wine and phylloxera in nineteenthcentury france. The Review of Economics and Statistics 92 (4), 714-728.

Bengtsson, N. (2010). How responsive is body weight to transitory income changes? evidence from rural tanzania. Journal of Development Economics 92 (1), 53-61.

Bhalotra, S. (2010). Fatal fluctuations? cyclicality in infant mortality in india. Journal of Development Economics 93 (1), 7-19.Currie, J. (2009). Healthy, wealthy, and wise: Socioeconomic status, poor health in childhood, and human capital development. Journal of Economic Literature 47 (1), 87-122.

Bozzoli, C. and C. Quintana-Domeque (2014). The weight of the crisis: evidence from newborns in argentina. Review of Economics and Statistics 96 (3), 550-562.

Burlando, A. (2014). Transitory shocks and birth weights: Evidence from a blackout in zanzibar. Journal of Development Economics 108, 154168.

Cameron, L. and M. Shah (2015). Risk-taking behavior in the wake of natural disasters. Journal of Human Resources 50 (2), $484-515$.

Cutler, D., A. Deaton, and A. Lleras-Muney (2006). The determinants of mortality. Journal of economic perspectives 20 (3), $97-120 . E b e n s t e i n$, A., M. Fan, M. Greenstone, G. He, P. Yin, and M. Zhou (2015). Growth, pollution, and life expectancy: China from 1991-2012. American Economic Review 105 (5), 226-31.

Evans, D. K., B. Holtemeyer, and K. Kosec (2019). Cash transfers and health: Evidence from tanzania. The World Bank Economic Review.

Kosec, K. and J. Song (2019). "The Effects of Income Fluctuations on Rural Health and Nutrition" Forthcoming, IFPRI Discussion Paper.

Lohmann, S. and T. Lechtenfeld (2015). The effect of drought on health outcomes and health expenditures in rural vietnam. World Development $72,432-448$

Hidrobo, M. (2014). The effect of ecuador's 1999 economic crisis on early childhood development. Economic Development and Cultural Change 62 (4), 633-671.

Hyland, M. and J. Russ (2019). Water as destiny: The long-term impacts of drought in sub-saharan africa. World Development 115, 30-45..

Luechinger, S. and P. A. Raschky (2009). Valuing flood disasters using the life satisfaction approach. Journal of Public Economics 93 (3-4), 620-633.

Minoiu, C. and O. N. Shemyakina (2014). Armed conflict, household victimization, and child health in côte d'ivoire. Journal of Development Economics 108, 237-255.

Van den Berg, G. J., M. Lindeboom, and F. Portrait (2006). Economic conditions early in life and individual mortality. American Economic Review 96 (1), 290-302.

This publication has not been independently peer reviewed. Any opinions expressed here belong to the author(s) and are not necessarily representative of or endorsed by IFPRI. 